\title{
Catalytic Pyrolysis of Dual Wastes into Worth
}

\author{
Ming-Zen Chang ${ }^{1}$, Chao-Chin Chan ${ }^{2}$, Yeuh-Hui Lin ${ }^{2, *}$
}

\begin{abstract}
Recycling of polymer waste is important both in the conservation of resources and the environment. A plastic waste was pyrolyzed over a series of post-use commercial catalysts using a fluidizing reaction system. Experiments carried out with these catalysts gave good yields of valuable hydrocarbons with differing selectivity in the final products text. Greater product selectivity was observed with a hybrid catalyst of MCM-41/CatR1 with more than $65.8 \mathrm{wt} \%$ olefins products.
\end{abstract}

Keywords-Recycling, waste, Catalyst, Pyrolysis, Selectivity

\section{Introduction}

Rapid growth of the world population led to increased demand of commodity plastics. Plastic pollution has become an indispensable ingredient of human life. The huge amount of waste plastics that resulted from the dramatic increase in polymer production with chlorinated content gives rise to serious environmental problems [1]. An economical improvement of processing the recycling using catalytic cracking can operate in mixing the plastic waste with fluid catalytic cracking (FCC) commercial catalysts [2-4]. Although spent FCC catalysts are classified as a non-hazardous waste, the quantity is significant and the exhausted catalyst constitutes an environmental solid residue. A more attractive process is that of adding plastic waste into the FCC process, under suitable process conditions with the use of zero-cost spent FCC catalysts, a large number of polymers can be converted into valuable hydrocarbons [5-7]. Therefore, it is the objective of this work to investigate an FCC reaction system using a series of waste FCC catalysts in the degradation of plastic waste with hazardous PVC mixture and for development of an alternative for achieving plastic recycling.

\section{Experimental}

In this study, a mixture of waste plastics was obtained from post-consumer polymer waste stream in South-Taiwan with the component of polyethylene $(\sim 62 \mathrm{wt} \% \mathrm{PE}=\sim 36 \mathrm{wt} \%$ HDPE + $26 \mathrm{wt} \%$ LDPE), polypropylene ( $\sim 34 \mathrm{wt} \% \mathrm{PP})$, polystyrene ( $\sim 3 \mathrm{wt} \%$ PS) and with about $1 \mathrm{wt} \%$ polyvinyl chloride (PVC) mixtures. The raw catalysts prepared are described in Table 1.

\footnotetext{
2,* Yeuh-Hui Lin, PhD, ${ }^{*}$ Corresponding author.

Department of Greenergy, Kao Yuan University

Kaohsiung, Taiwan, ROC
}

${ }^{1}$ Ming-Zen, Chang, $\mathrm{PhD}$

Department of Applied Foreign Languages, Kao Yuan University

Kaohsiung, Taiwan, ROC

${ }^{2}$ Chao-Chin Chan, $\mathrm{PhD}$

Department of Greenergy, Kao Yuan University

Kaohsiung, Taiwan, ROC
Table 1. Catalysts used in the catalytic degradation of postconsumer waste polymers.

\begin{tabular}{|l|c|c|c|c|}
\hline \multirow{2}{*}{ Catalyst } & \multirow{2}{*}{ Si/Al } & \multicolumn{3}{|c|}{ Surface area $\left(\mathbf{c m}^{2} / \mathbf{g}\right)$} \\
\cline { 3 - 5 } & & BET $^{\mathrm{a}}$ & Micropore & External \\
\hline $\begin{array}{l}\text { Cat-R1/ } \\
\text { Cat-S1 }\end{array}$ & 2.1 & 147 & 103 & 44 \\
\hline ZSM-5 & 17.5 & 375 & 257 & 118 \\
\hline HUSY & 5.7 & 472 & 375 & 118 \\
\hline MCM-41 & 14.3 & 815 & 0 & 815 \\
\hline
\end{tabular}

A series of reused FCC catalysts, including Cat-R1 (a recycle FCC catalyst with regeneration), Cat-S1 (a spent FCC catalyst without regeneration), HCat-Z/R (a hybrid catalyst prepared using a ratio of $45 \mathrm{wt} \% \mathrm{ZSM}-5,45 \mathrm{wt} \%$ Cat-R1 and $10 \mathrm{wt} \%$ ludox to act as a bonding agent and a diluent), HCatY/R (a hybrid catalyst of $45 \mathrm{wt} \%$ HUSY, $45 \mathrm{wt} \%$ Cat-R1 and $10 \mathrm{wt} \%$ ludox) and HCat-M/R (a composite catalyst of 45 wt\% MCM-41, 45 wt\% Cat-R1 and 10 wt\% ludox). The catalyst $(\sim 5 \mathrm{~g})$ was then dried by heating in flowing nitrogen $\left(50 \mathrm{ml}\right.$ min-1) to $120^{\circ} \mathrm{C}$ at $60^{\circ} \mathrm{C} \mathrm{h}-1$. After 2 hours the temperature was increased to $520^{\circ} \mathrm{C}$ for 5 hours at a rate of $120^{\circ} \mathrm{C} \mathrm{h}^{-1}$ to activate the catalyst.

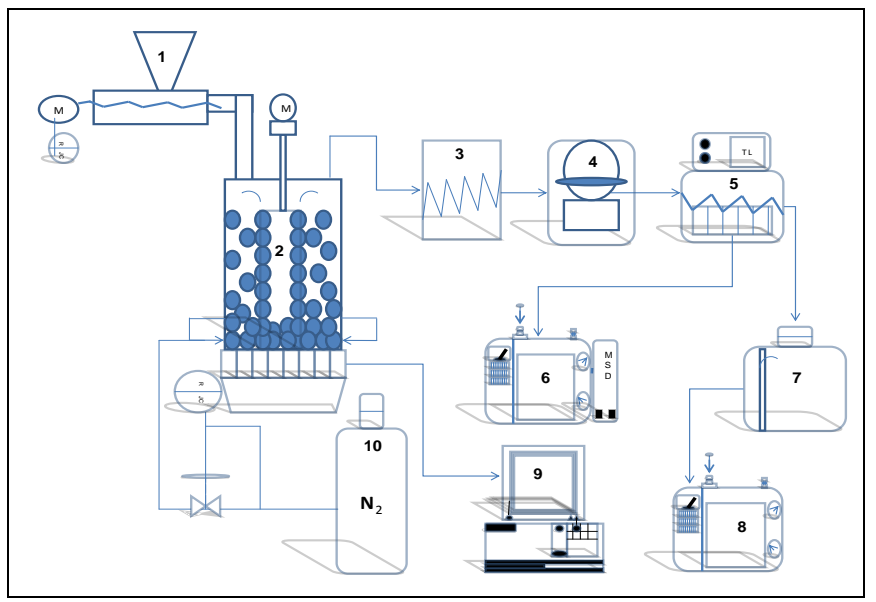

Fig. 1. Schematic diagram of the catalytic degradation of waste plastics in a fluidizing reaction system.

A process flow diagram of the experimental system is given elsewhere [8] and shown schematically in Figure 1. Gaseous hydrocarbon products were analyzed using a gas chromatograph equipped with a thermal conductivity detector (TCD) fitted with a $1.5 \mathrm{~m} \times 0.2 \mathrm{~mm}$ i.d. Molecular Sieve $13 \mathrm{X}$ packed column and a flame ionization detector (FID) fitted 
with a $50 \mathrm{~m} \times 0.32 \mathrm{~mm}$ i.d. PLOT $\mathrm{Al}_{2} \mathrm{O}_{3} / \mathrm{KCl}$ capillary column. The solid remaining deposited on the catalyst after the catalytic degradation of the polymer was deemed "residues" and contained involatile products and coke. The amount and nature of the residues was determined by thermogravimetric analysis (TGA).

\section{Results and Discussion}

\subsection{Effect on Catalyst Performance}

Both the carbon number distribution of the products of waste plastics cracking at $390^{\circ} \mathrm{C}$ over various recycled catalysts and the nature of the product distributions were found to vary with the catalyst used. As shown in Table 2, a large amount of solid residue, unconverted commingled plastic mixture and high molecular weight degradation products, remained on the spent catalyst was observed at $390^{\circ} \mathrm{C}$ for the mixture of commingled plastic degradation over Cat-S1 (a spent catalyst from refinery FCC units without reactive process). As also can be seen in Table 2, the conversion was only $16.2 \mathrm{wt} \%$ for Cat-S1 compared with $82.5 \mathrm{wt} \%$ when regenerated and reactive FCC commercial catalyst (Cat-R1) was used. Both acidity and diffusion constraints associated with fluidization condition of mass transfer effect within individual micropores of each catalyst may play significant roles in the observed product distribution. A large amount of solid residue, presumably unconverted commingled plastic waste and high molecular weight degradation products, remained on the Cat-S1 catalyst at $390^{\circ} \mathrm{C}$. Consequently, thermal degradation productions arising from PVC and PS species were observed showing primary cracking products ( $\mathrm{HCl}$ and styrene) and an even spread of carbon numbers consisting of volatile hydrocarbon products $\left(\mathrm{C}_{1}-\mathrm{C}_{4}=7.8 \mathrm{wt} \%\right.$ and $\left.\mathrm{C}_{5}-\mathrm{C}_{9}=5.4 \mathrm{wt} \%\right)$ with some isomerization of BTX (0.4 $\mathrm{wt} \%)$. The bulk of the products observed with the recycled catalysts (Cat-R1) and these hybrid catalysts of HCat-Z/R (ZSM-5/Cat-R1), HCat-Y/R (HUSY/Cat-R1) and HCat-M/R (MCM-41/Cat-R1) were in the gas phase with less than $6 \mathrm{wt} \%$ liquid collected. Overall, the yield of volatile hydrocarbons for the zeolite-added hybrid catalysts (HCat-Z/R > HCat-Y/R) gave higher yield than amorphous hybrid catalyst (HCat-M/R) and reused equilibrium FCC catalyst (Cat-R1), and the highest (87.4 wt\%) was obtained for HCat-Z/R. The differences in the product distributions between those catalysts can be seen with HCat-Z/R producing a much more $\mathrm{C}_{1}-\mathrm{C}_{4}$ hydrocarbon gases (51.4 wt\%) than HCat-Y/R, HCat-A/R and Cat-R1 catalysts. Some similarities were observed between Cat-R1 and HCat$\mathrm{A} / \mathrm{R}$ with $\mathrm{C}_{1}-\mathrm{C}_{4}$ and $\mathrm{C}_{5}-\mathrm{C}_{9}$ yields, which were approximately 24-27 wt $\%$ and 52-54 wt\%, respectively. By comparison, much higher level of unconverted plastic was observed with HCat-M/R and Cat-R1 about 10-11 wt\%, while the highest coke yields were observed with HCat-Y/R (5.9 wt\%). The major products of polystyrene cracking over various catalysts were styrene at about 3-4 wt\% with light aromatics (such as benzene, toluene, ethyl-benzene and xylenes etc.) and smaller chain volatile hydrocarbons. The major products of PVC cracking over various catalysts were hydrogen chloride with light aromatics and smaller chain olefins and paraffins, and with some amount of residue products deposited on the catalyst.

As can be seen in Table 2, the chlorine was chemically separated from the PVC component (1 wt \% in plastic mixture with $0.53 \% \mathrm{Cl}$ calculated from element analysis) and as a hydrochloric acid $(\mathrm{HCl})(0.3 \sim 0.5 \mathrm{wt} \%)$ in de-ionized water system derived from volatile products (about $60 \%$ and up to 95\% Cl content) and deposited/captured by residue products (about 5 40\% Cl content).

Table 2. Catalysts used in the catalytic degradation of postconsumer waste plastics

\begin{tabular}{|c|c|c|c|c|c|}
\hline & \multicolumn{5}{|c|}{ Catalyst type } \\
\hline & Cat-R1 & Cat-S1 & $\begin{array}{c}\text { HCat- } \\
\text { Z/R }\end{array}$ & $\begin{array}{c}\text { HCat- } \\
\text { Y/R }\end{array}$ & $\begin{array}{c}\text { HCat- } \\
\text { M/R }\end{array}$ \\
\hline \multicolumn{6}{|c|}{ Yield ( wt\% feed ) } \\
\hline Gaseous & 82.5 & 15.4 & 87.5 & 85.1 & 84.2 \\
\hline Liquid $^{\mathrm{a}}$ & 5.3 & 1.6 & 4.4 & 3.9 & 5.8 \\
\hline Residue $^{b}$ & 9.2 & 81.4 & 5.1 & 4.7 & 8.3 \\
\hline Coke & 2.5 & 1.1 & 2.7 & 5.9 & 3.1 \\
\hline $\mathrm{HCl}$ & 0.5 & 0.5 & 0.3 & 0.4 & 0.3 \\
\hline $\begin{array}{c}\text { Light gases } \\
\left(\mathrm{C}_{1} \sim \mathrm{C}_{4}\right)\end{array}$ & 23.9 & 7.8 & 51.4 & 32.2 & 27.5 \\
\hline $\begin{array}{l}\text { Gasoline } \\
\left(\mathrm{C}_{5} \sim \mathrm{C}_{9}\right)\end{array}$ & 53.8 & 5.4 & 30.7 & 49.3 & 52.0 \\
\hline Styrene & 3.6 & 1.8 & 3.9 & 3.3 & 4.2 \\
\hline BTX $^{c}$ & 1.4 & 0.4 & 1.1 & 0.7 & 0.5 \\
\hline
\end{tabular}

Greater product selectivity was observed with a hybrid catalyst of MCM-41/Cat-R1 with more than $65.8 \mathrm{wt} \%$ olefins products. The chlorine-containing products shown in the distribution of gaseous hydrocarbons are not detectable in this study. Hence, this study gives promising results as an alternative technique for the cracking and recycling of polymer waste. The controlling catalytic factors for PVC degradation will be associated with the number of accessible spaces in related to the cracking ability deactivated by coke content and the total number of acid sites. The results indicate that although the initial cracking of plastic waste must be confined to the external surface and pore mouths of the cracking catalysts, the resultant initial cracked products are then degraded further within the catalyst. The rate of gaseous hydrocarbon evolution further highlights the slower rate of 
degradation over HCat-M/R and Cat-R1 as shown in Figure 2 when comparing all catalysts under the conditions at $390^{\circ} \mathrm{C}$.

For Cat-S1, the yield and initial rate of gaseous production was significantly decreased and lower during the course of reaction and the time for plastic waste to be degraded lengthened until the end of total collection time. The maximum rate of generation was observed after 2 min with the zeolite-based composite catalysts (HCat-Z/R and HCat-Y/R), whereas the maximum was observed after 3 min with the CatR1 and HCat-M/R catalysts. The systematic experiments discussed in this work indicate that catalyst deactivation is being produced by active-site coverage, and consequently decrease the activity of the catalyst, giving the reason of decreasing of reaction rate with reaction time.

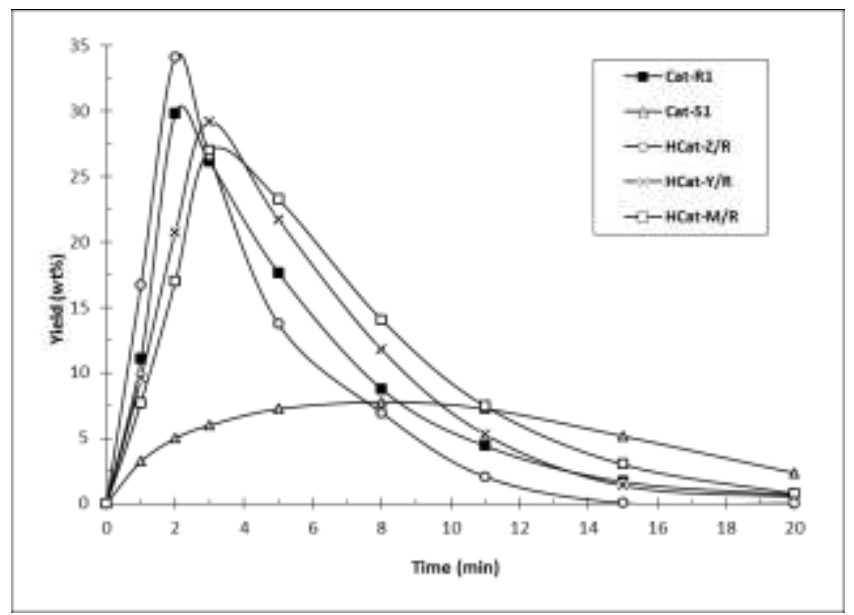

Fig. 2 Comparison of hydrocarbon yields as a function of time for the catalytic degradation of post-consumer waste plastics at $390^{\circ} \mathrm{C}$ over different catalysts.

The systematic experiments discussed in this work and in earlier work [9-11] indicate that catalyst deactivation is being produced by active-site coverage, and consequently decrease the activity of the catalyst, giving the reason of decreasing of reaction rate with increasing the amounts of residues.

\subsection{Effect on Reaction Conditions}

The rate of hydrocarbon production as a function of time at five temperatures is compared in Fig. 3 and as expected, faster rates were observed at higher temperatures. At $450^{\circ} \mathrm{C}$, the maximum rate of hydrocarbon production was $37 \mathrm{wt} \%$ after only $2 \mathrm{~min}$ with all the plastic degraded after approximately $8 \mathrm{~min}$. As the temperature decreased, the initial rate of hydrocarbon production dropped and the time for the polymer to be completely degraded lengthened. At $330^{\circ} \mathrm{C}$, the rate of hydrocarbon production was significantly lower throughout the whole reaction with the polymer being degraded over 20 min.

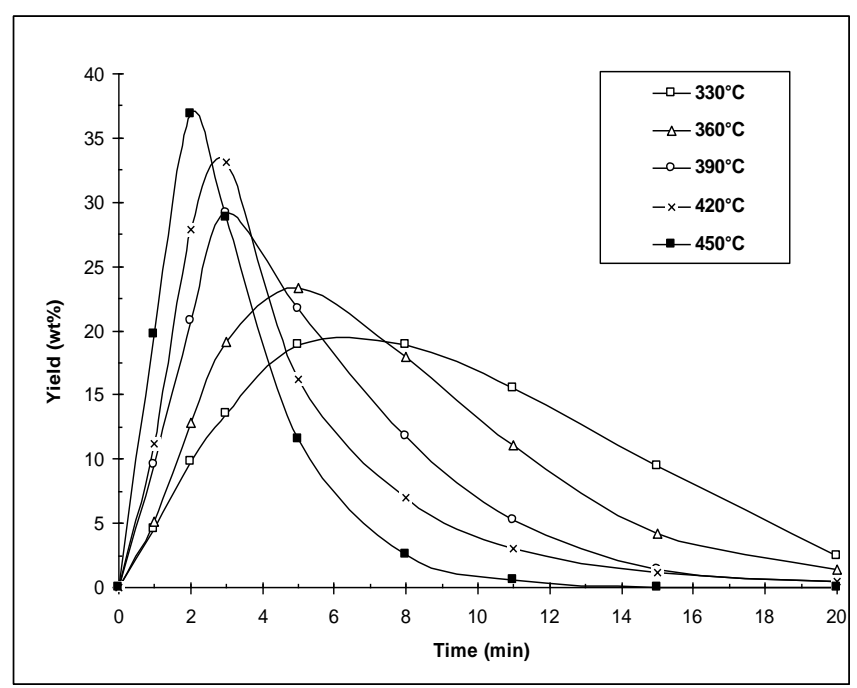

Fig. 3 Comparison of hydrocarbon yields as a function of time at different reaction temperatures.

Both acidity and diffusion constraints within individual micropores of each catalyst may play significant roles in the observed product distribution. The results shown in Fig. 4 illustrate that for efficient plastic waste degradation good mixing is required, with a dramatic drop-off in the rate of degradation observed only at the lowest fluidizing flow used $\left(300 \mathrm{ml} \mathrm{min}^{-1}\right)$.

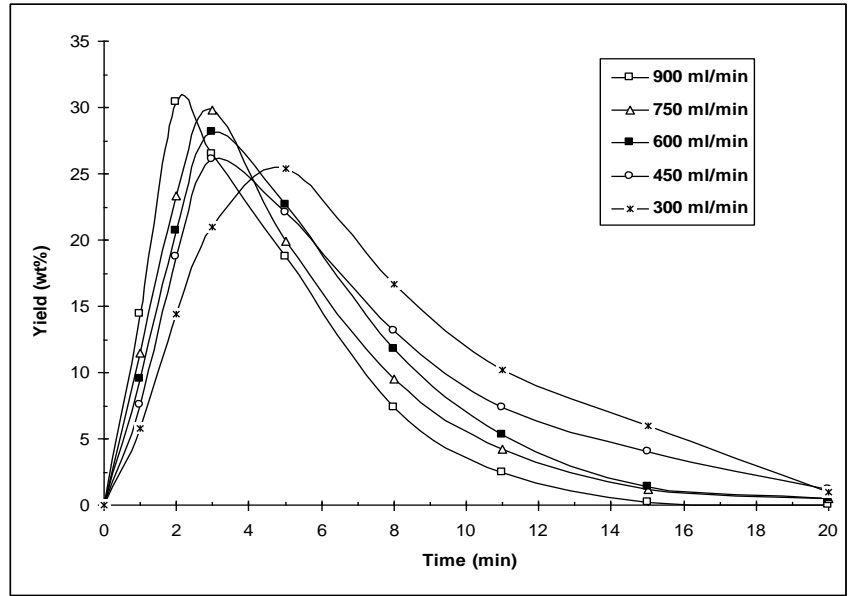

Fig. 4 Comparison of hydrocarbon yields as a function of time at different fluidization gas.

Furthermore, changing the fluidizing flow rate influences the product distribution. At low flow rates, secondary products are observed with increased amounts of coke precursors although the overall degradation rate is slower as shown by increasing amounts of partially de-polymerized products. The amount of Cat-R1 used in the degradation of post-consumer plastic mixture remained constant and, therefore, as more waste plastics was added to the reactor then fewer catalytic sites per unit weight of catalyst were available for cracking. The overall effect of increasing the catalyst to plastic ratio from $0.1: 1$ to $0.6: 1$ on the rate of hydrocarbon 
generation was small but predictable. As the catalyst to plastic ratio decreases, the possibility of post-consumer plastic adhesion to the reactor wall increases as the amount of unreacted polymer waste in the reactor rises. However, for the work carried out in this paper no such problems were observed. The total product yield after 20 minutes showed only a slight downward trend even after a 10 fold increase in added plastic waste. This can be attributed to the sufficient cracking ability of Cat-R1 and excellent contact between post-consumer plastic mixture and catalyst particles. For comparison, the use of this reaction system coped with these hybrid FCC catalysts (HCat-Z/R, HCat-Y/R and HCat-M/R) can be a better option since it can gives a good conversion and even its activity is lower than that of the typical acid-cracking catalysts, this can be compensated by increasing the catalyst to plastic ratio [12]. Especially, due to the steric and diffusional hindrances posed by the bulky nature of plastic molecules to enter the catalyst micropores, mixed catalysts based on bimodal microporemesopore structures were used in this current work showing enhanced activities for obtaining the desired selectivity.

\section{Conclusions}

In this study, for the conversion of plastic waste to valuable hydrocarbons, an economical improvement of processing the recycling via catalytic cracking would operate in mixing the post-commercial plastic waste with post-use FCC catalysts. The selectivity could be further influenced by changes in reactor conditions; in particular, olefins and isoolefins were produced by low temperatures and short contact times. Experiments carried out with various catalysts gave good yields of volatile hydrocarbons with differing selectivity in the final products dependent on reaction conditions.

Moreover, the production of olefins with potential value as a chemical feedstock is economically attractive and may offer greater profitability than production of saturated hydrocarbons and aromatics. Therefore, the method used shows an adequate alternative in minimization of hazardous waste handling costs and optimization of gasoline range products for a wide range of waste plastic mixtures. The selectivity could be further influenced by changes in reaction temperature, ratios of polymer to catalyst feed and flow rates of fluidizing gas. It is concluded that under appropriate reaction conditions and suitable catalysts can have the ability to control both the product yield and product distribution from polymer degradation, potentially leading to a cheaper process with more valuable hydrocarbons.

\section{Acknowledgment}

The authors would like to thank the National Science Council (NSC) of the Republic of China (ROC) (NSC 1042221-E-244-015 for kindly financial supports.

\section{References}

[1] Al-Salem, S.M., Lettieri, P., and Baeyans J., "Recycling and recovery routes of plastic solid waste (PSW): A review," Waste Management, Vol. 29, pp. 2625-2643, 2009.

[2] Lin, Y.H. and Yang, M.H., "Catalytic conversion of commingled polymer waste into chemicals and fuels over spend FCC commercial catalyst in a fluidised-bed reactor," Applied Catalysis B: Environmental, Vol. 69, pp. 145-153, 2007.

[3] Lin, Y.H. and Yang, M.H. "Fluidised bed pyrolysis of cracking catalysts for producing hydrocarbons," Polymer Degradation and Stability, Vol. 89, pp. 101-108, 2005.

[4] Lin, Y.H., Yang, M.H., Yeh, T.F., Ger, M.D., "Catalytic degradation of high density polyethylene over mesoporous and microporous catalysts in a fluidised-bed reactor," Polymer Degradation and Stability, Vol. 86, pp. 121-128, 2004.

[5] Lin, Y.H. and Yang, M.H., "Catalytic Pyrolysis of polyolefin waste into valuable hydrocarbons over reused catalyst from refinery FCC units," Applied Catalysis A: General, Vol. 328, pp 132-139, 2007.

[6] Lin, Y.H. and Yang, M.H., "Chemical catalysed recycling of PP over a spent FCC catalyst and various commercial cracking catalysts using TGA," Thermochimica Acta, Vol. 470, pp 52-59, 2008.

[7] Lin, Y.H. and Yang, M.H., "Tertiary recycling of commingled polymer waste over commercial FCC equilibrium catalysts for producing hydrocarbons," Polymer Degradation and Stability, Vol. 94, pp 25-33, 2009.

[8] Lin, Y.H., Yang, M.H., Wei, T.T., Hsu, C.T., Wu K.J., Lee S.-L.,"Acid-catalyzed conversion of chlorinated plastic waste into valuable hydrocarbons over post-use commercial FCC catalysts," Journal of Analytical and Applied Pyrolysis, Vol. 87, pp 154-162, 2010.

[9] Wei, T.T., Wu, K.J., Lee, S.-L., and Lin, Y.H., "Chemical recycling of post-consumer polymer waste over fluidizing cracking catalysts for producing chemicals and hydrocarbons," Resource Conservation and Recycling, Vol. 54, pp 952-961, 2010.

[10] Lin, Y.H., Tseng, C.-C.; Wei, T.-T. and Hsu, C.-T., "Recycling of dual hazardous wastes in a catalytic fluidizing process," Catalysis Today, vol. 174, pp 37-45, 2011.

[11] Wei, T.T. and Lin, Y.H., "Fast pyroylysis of polyolefin waste over cracking catalysts for producing hydrocarbon fuels using a fluidized-bed reactor," International Journal of Chemical Reactor Engineering, Vol. 10, No.1 , 2012

[12] Wei, T.T. Lin, Y.H., "A waste catalyst for a hazardous chlorine-containing plastic waste" Environmental Engineering \& Management Journal, 2015, In press. 